\title{
Implementing a university-wide credit-bearing English language enhancement program: Issues emerging from practice
}

\author{
Ben Fenton-Smith ${ }^{\mathrm{a}}$, Pamela Humphreys ${ }^{\mathrm{b}}$, Ian Walkinshaw ${ }^{\mathrm{a}}$, Rowan Michael ${ }^{\mathrm{a}}$ and Ana Lobo ${ }^{\mathrm{a}}$ \\ ${ }^{a}$ School of Languages and Linguistics, Griffith University, Brisbane, Australia; ${ }^{b}$ Griffith \\ English Language Institute, Griffith University, Brisbane, Australia.
}

\begin{abstract}
Many nations now enrol large numbers of tertiary students with English as an additional language (EAL), raising concerns over academic literacy standards. As a result, calls for wholeinstitution approaches to enhance language proficiency have grown. This paper describes the issues faced by one university that attempted such an approach. We first outline three theoretical assumptions, i.e. that academic literacy is facilitated by (1) the attention to discourse at the discipline-specific level, (2) the engagement of students with their social, institutional and cultural surroundings, and (3) the provision to students of the tools for self-directed, ongoing learning. The paper then explains how one Australian university implemented a mandatory program of credit-bearing discipline-specific English language enhancement courses (ELECs) as foundational units across all degree programs. Describing the first program of its kind in Australia, the paper focuses on the issues emerging from practice identified from the first five years: (1) stakeholder perceptions, (2) student reception, (3) materials development, (4) program management, (5) assessment, and (6) measuring outcomes. Rather than a panacea for a notoriously complex issue, the paper presents strategies for dealing with the challenges that emerge for other institutions that might be contemplating reform of a similar magnitude.
\end{abstract}

\section{Keywords}

academic literacy; English as an additional language (EAL); English for academic purposes; English language enhancement, higher education; English as a Medium of Instruction (EMI)

\section{Introduction}

From 2000 to 2010, the number of foreign students globally increased by a staggering 99\%. By 2012, 4.5 million tertiary students were enrolled in institutions outside their country of citizenship (OECD 2014) and a doubling of this to 8 million is projected by 2020 (Forest and Altbach 2006). Anglophone countries are popular destinations, attracting over $42 \%$ of all cross-border students (OECD 2013) with the US enjoying the largest global share at 16.5\%, followed by the UK (13\%), Australia (6\%), and Canada (5\%) (OECD 2013). As cultural and linguistic diversity ramps up, English medium of instruction (EMI) universities in particular are realising that traditional approaches to learning and teaching must change.

Pointedly, the academic literacy needs of students for whom English is an additional language ('EAL' is the term current in Australia to refer to this cohort) have become a specific focus of attention globally. Australian higher education was stirred by a report by Birrell, Hawthorne and Richardson (2006) which claimed that many international students entered - and exited - Australian universities with inadequate language proficiency.

\footnotetext{
* Corresponding author. Email: b.fenton-smith@griffith.edu.au
} 
Similarly, the UK national tertiary regulator, the Quality Assurance Agency, reported on a perceived downgrading of the university experience for domestic students due to the number of international students with 'poor' English (QAA 2009). Hong Kong initiated testing of English proficiency at graduation in 2002 at eight EMI institutions due to perceptions that students' language standards were in decline (Zhengdong 2009). The US has been less active in this space, perhaps because the pro rata effect of EAL students at just $4 \%$ (Cho and $\mathrm{Yu}$ 2015) is less evident than in the UK or Australia.

\section{Part 1: University-wide strategies}

As a result of the above, calls for whole-institution approaches to academic literacy have grown (e.g. Dunworth, Drury, Kralik and Moore 2014, Kennelly, Maldoni and Davies 2010, Murray and Nallaya 2014, Sheridan 2011, Wingate 2006). However, there are many impediments to innovation on that scale. Wingate $(2006,459)$ points out that major change in UK institutions is stymied by "the organisational and managerial challenges in coordinating progressive skills development throughout degree courses", not to mention the mountainous task of securing "the commitment of all academics teaching in degree courses" and the level of "staff consultation and development measures" that would be required to get there. In the higher education sectors of other Anglophone nations, such as Australia (Arkoudis and Starfield 2007) and Ireland (Sheridan 2011), there are reports of ad hoc programs or organisational resistance to university-wide strategies, while in New Zealand, the Academic Quality Agency audit framework does not even mention English language proficiency (AQA 2013).

The US context is more complex. On the one hand, universities are steeped in the institution-wide tradition of 'rhetoric and composition', which is typically a mandatory, across-the-board first-year course in general writing. But this approach is neither disciplinespecific nor EAL student-focused, and is typically confined to written expression. A secondary approach, variously labelled 'Writing Across the Curriculum' (WAC) and/or 'Writing in the Disciplines' (WID), does focus on discipline-specific genres, but it was not designed for EAL students (Hall 2009). Moreover, only about half of US universities deliver a WAC/WID program and they are not necessarily institution-wide (Thaiss and Porter 2010).

A study by Dunworth et al. (2014) identifies several factors that are common to successful institution-wide strategies for promoting students' academic language growth. They are:

- Leadership: chaired by a senior member of university hierarchy.

- Expertise: advised by linguistic and disciplinary experts.

- Consultation: negotiated with/through key stakeholders.

- Time: granted sufficient time for implementation.

- Unity: unencumbered by tensions between vested interests.

- Resourcing: assured of sufficient resources for implementation and maintenance.

- Educational integrity: built on a sound theoretical, scholarly and evidential base.

- Sustainability: integrated into the daily running of the institution (not a short-term project with little meaningful traction).

This list makes clear the multi-faceted requirements for realising an institutional language enhancement plan. While the participants in the Dunworth et al. (2014) study reported "an overwhelming sense that a whole of institution approach was the most effective way of 
achieving progress” (11), the authors point out the need for further evaluations of actual initiatives attempted in the tertiary sector.

The current paper addresses this deficit, describing how one Australian university confronted the issue of academic language and literacy in its EAL student cohort by implementing a mandatory program of credit-bearing discipline-specific English language enhancement courses (ELECs). In doing so, the paper outlines the theoretical background of the model (Part 2), explains the context, structure and content of the ELECs (Part 3); and articulates the core issues emerging from practice (Part 4).

\section{Part 2: Theoretical background}

In this section we turn to theoretical issues currently influencing the practice of academic language enhancement in higher education. Firstly, it must be acknowledged that the nomenclature and constructs of 'academic language' or 'academic literacy' are contested due to varying epistemological beliefs. It is beyond the scope of this paper to detail these differences but we will briefly clarify the position on 'academic language and literacy' adopted in this paper. We accept the multidimensional conceptualisations of language drawn from the communicative, interactional and symbolic competences frameworks from the field of Second Language Acquisition (Bachman and Palmer 2010; Canale 1984; Canale and Swain 1980; Kramsch 1986, 2006). Additionally, our view draws on key theories and traditions situated in academic settings: that is, pragmatic and critical English for Academic Purposes (EAP) (Benesch 2001; Hyland 2006, 2013; Pennycook 1997), register/genre theory (Mahboob, Dreyfus, Humphrey and Martin 2010; Swales 1990, 2011), and the Academic Literacies approach (Lea and Street 1998, 2006). The latter incorporates but moves beyond surface features of a 'study skills' model and even beyond the academic conventions of 'academic socialisation' to encompass 'academic literacies' (plural), recognising the impact of institutional practices, power relations and social identities on students' development. For the sake of parsimony, however, we will henceforth use the term 'EAP' with the intention of incorporating the above.

The pedagogical model described here was formulated around three key principles drawn from the above frameworks and approaches. They are that academic literacy in higher education is facilitated by:

1. the attention to discourse at the discipline-specific level;

2. the engagement of students with their social, institutional and cultural surroundings;

3. the provision to students of the tools for ongoing learning.

Each principle is considered in turn with regard to an institution-wide strategy and the consequences that flow from it.

\section{The attention to discourse at the discipline-specific level}

The notion that academic discourse differs by discipline is well-accepted. As Hyland (2002, 352) notes: "academic writing is not a single undifferentiated mass, but a variety of subjectspecific literacies". Instructional approaches grounded in the traditions of EAP (Hyland 2006, 2013) and register/genre theory (Mahboob, Dreyfus, Humphrey and Martin 2010; Swales 1990, 2011) have made great progress in the operationalisation of discipline-specific discourse within curricula. Under the umbrella term 'Genre/EAP', Wingate and Tribble (2012, 486) summarise this orientation as offering "systematic accounts of the range of genres which are associated with higher education social practices” and implementing 
"pedagogic responses to learners' needs in these contexts". However, the manifestation of true discipline-specificity in the form of, for example, a standalone EAP course, is easier said than done, as we illustrate in this paper. The problem, as Hyland and Hamp-Lyons (2002, 5) point out, is that

there are obstacles to putting specificity into practice. Not least among these involves juggling institutional constraints such as achieving viable group size, bargaining time and learning priorities with content departments, and ensuring comparability across disciplines.

As Figure 1 shows, in theory there is no limit to how narrowly an EAP course can focus on disciplinary discourse. Even individual courses generate their own discursive microclimates, and individual assessment items may have characteristic language features. In an ideal world, therefore, it may be more pedagogically effective to focus at the narrowest and most discipline-specific level. But the pragmatic reality is that the higher the degree of specificity, the greater the administrative complexity and financial outlay.

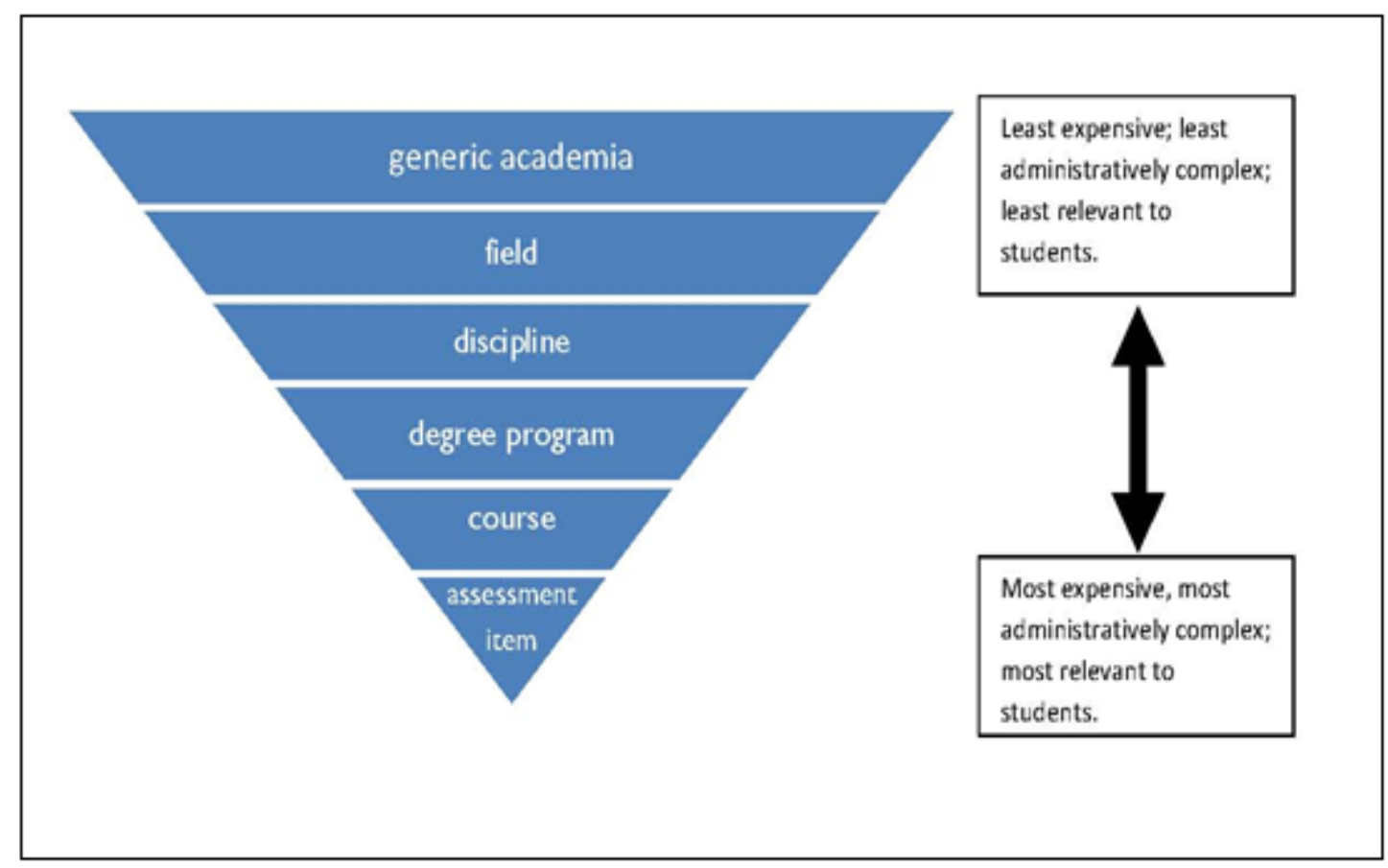

Figure 1. The calibration of discipline-specificity in EAP.

We revisit these issues in Parts 3 and 4, when we discuss the challenges of reconciling discipline-specific ideals with institutional constraints.

2. The engagement of students with their social, institutional and cultural surroundings

Duff (2010) argues that 'socialisation' refers to more than mere apprenticeship into the use of academic language, since academic language is the product of wider contextual forces, which students have to negotiate. Where those students are 'international' (that is, studying in a country other than their own), they are faced with the challenge of 'fitting in' to a national culture, a higher education culture, and a disciplinary culture, as illustrated in Figure 2: 


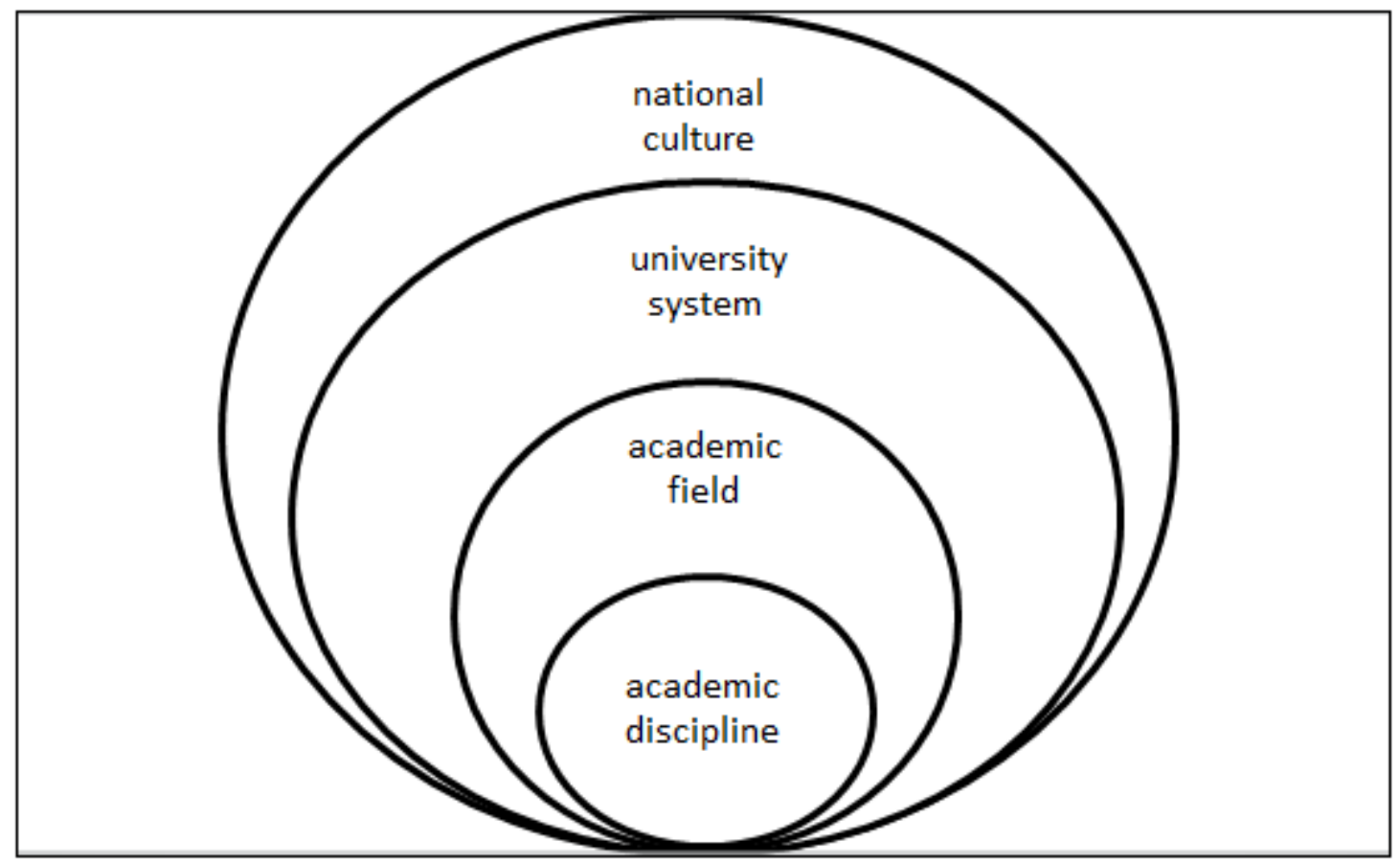

Figure 2. Levels of academic socialisation.

This so-called 'assimilationist' perspective (Sheridan 2011) on socialisation is not uncontroversial. For example, Marginson, Nyland, Sawir and Forbes-Mewett (2010, 440) have observed of the Australian university culture that "most of the discussion has been about changing international student behaviour to enhance adjustment, which in practice means bringing them into line with local values and behaviours". The question is whether students are 'forced' to fit in with western academic norms and discourses, or whether this is actually what they desire. Recent literature (Sheridan 2011; Zepke and Leach 2010) attempts to synthesise these competing notions. On the one hand, it is recognised that international students are under pressure to acculturate. But at the same time, institutions need to take stock of and harness the cultural capital brought by these students, particularly by recognising and actively promoting their role as agents of change in the internationalisation of campus and curriculum. This dual perspective is adopted in the model described here.

\section{The provision to students of the tools for ongoing learning}

This third point emphasises the importance of self-efficacy for academic success (Habel 2009). A study of 798 international university students by Rochecouste, Oliver, Mulligan and Davies (2011) found that confidence, motivation and positive thinking were key affective factors in student advancement. This concurs with Nunan's $(1997,192)$ statement that "developing some degree of autonomy is essential if learners are to become effective language users, and that the ability to direct one's own learning can be developed through pedagogical procedures.” Viewed within an academic literacies model (Lea and Street 2006), self-efficacy is crucial for gaining familiarity with institutional/disciplinary practices, and for developing students' social identity and awareness of the broader institutional hierarchy (cf. Sheridan 2011). 
Where academic language development is concerned, however, the capacity for selfdirected learning is not a given. Students may avoid independently seeking out opportunities on campus for assistance, particularly if they are low-performers (Arkoudis, Baik, and Richardson 2012; Wingate 2006). Struggling students are more likely to study more than to seek outside language support (O'Loughlin and Arkoudis 2009; Wilkinson 2013), which they may view as unnecessarily increasing their workload (Wingate 2006).

The operationalisation of the above three principles in course design within a sustainable institution-wide strategy is discussed in the next two parts.

\section{Part 3: Explanation of English language enhancement courses}

\section{Significance of the ELEC approach}

Because institution-wide approaches to academic language development are rare, they attract attention where attempted. In Australia, this is particularly the case since the 2009 publication of the Department of Education, Employment and Workplace Relations (DEEWR) Good Practice Principles for International Students in Australian Universities, which recommended that tertiary providers adopt "an overall philosophy and systematic plan for English language development endorsed by senior management” (DEEWR 2009, Document 2, 9). The ELEC program represents one of the first actioned responses to this call in the Australian tertiary sector and as such there is widespread interest in any lessons learned. By way of illustration, its commencement was heralded in the national press (this from The Australian newspaper):

Griffith University has introduced a mandatory English language enhancement course for international students with merely competent English. Starting this semester, the program is being watched by other universities as the government moves to raise English standards for skilled migrants (Trounson, 2010).

Nowhere else in Australia have compulsory discipline-specific EAP courses been implemented as foundational units across all degree programs and, as argued above, such programs are atypical internationally.

\section{Institutional background}

Griffith University is a comprehensive multi-campus Australian university. Approximately one quarter of its 44,000 students are EAL, hailing from numerous countries, predominantly Asia. At the time of writing, the minimum language entry requirement to undergraduate degrees was IELTS 6.0 (no subscore below 5.5) or accepted equivalent. However, fewer than $20 \%$ of students enter via a formal language proficiency test as multiple entry pathways are common in the Australian context. Although the university offers pre-sessional EAP courses, they are only undertaken by $10-15 \%$ of students who have not met the minimum language condition for entry. A further one third of commencing undergraduates have completed a relevant diploma onshore prior to articulating into their second year of a bachelor program. Those who have met the language condition by taking a formal proficiency test offshore may arrive directly from overseas, as may those who have gained entry under the 'language of instruction' policy as a result of having studied for the requisite number of years in an English medium context. These multiple entry pathways inevitably mean it can be challenging to be sure of academic language proficiency levels on articulation to the degree program. This is a reality that many institutions are required to grapple with. 
In 2008, the University formed an English Language Working Party (ELWP), comprising senior academic/managerial staff from all four academic groups (business and commerce; health; sciences; and arts and social sciences) as well as from the Secretariat, representatives of the School of Languages and Linguistics (LAL), and the Griffith English Language Institute (GELI). This team formulated a university-wide English language enhancement strategy comprising five strands to develop academic literacy in EAL students throughout the student lifecycle, with the ELEC program as its pivotal element (see http://www.griffith.edu.au/international/english-enhancement-course/overarching-strategypolicies).

\section{ELEC program structure and content}

The program consists of four credit-bearing EAP courses lasting one semester and providing four hours of formal instruction per week in lecture/tutorial format as per the institutional standard structure of a course within a degree program. Each course is tailored at the macrofield level for the four academic groups:

- Language and Communication for Business and Commerce

- Language and Communication for Health

- Language and Communication for Sciences

- Language and Communication for Arts and Social Sciences

As these titles attest, discipline-specificity is approximated but not fully realised, since the courses are demarcated by 'field' rather than 'discipline'. Language and Communication for Health, for example, encompasses nursing, social work, psychology, exercise science and other subjects.

The ELECs are compulsory for EAL students who enter the university with an Overall IELTS score of 6.0 or 6.5 (or accepted equivalent) or who enter via a pathway which does not require English language testing as described above. The fact that the ELECs are mandatory ensures institution-wide reach and avoids a pitfall reported repeatedly in the literature: that optional support programs tend to be avoided by the students who need them most (Blackmore, Gribble, Farrell, Rahimi, Arber and Devlin 2014; Fenton-Smith and Michael 2013; Wingate, Andon and Cogo 2011). Each semester, between 500 and 1200 students take an ELEC. Degree program rules were changed in all undergraduate programs where the entry level was IELTS $<7$ so that ELECs might be undertaken in the first semester of study. This delays one core subject, but degree length is unaffected because students take one less elective in later years.

The ELEC program is jointly developed and delivered by the University's academic and professional providers of English language. On the academic side, LAL provide theoretical content through lectures, while on the professional side, GELI deliver practical, disciplinespecific language-oriented tutorials.

The curriculum's three core aims mirror the three issues discussed in Part 2:

1. To develop the communicative competence in English of students in an academic and specific disciplinary context, including producing, interpreting, analysing and participating in text (i.e. authentic spoken or written discourse in a particular genre). 
2. To raise students' awareness of the features and expectations of the Australian higher education system that underpin academic language and learning and of their role as change agents in the internationalisation of that system.

3. To foster students' capacity to develop their academic language competency and learning skills throughout the course of their degree program.

The fact that the program is institution-wide makes the ELEC model distinctive. Moreover, it incorporates the ingredients of Dunworth et al.'s (2014) framework of 'success factors':

- Leadership: The program was instigated by the Deputy Vice Chancellor (Academic) and ratified by the university executive, ensuring support and leadership at the highest level.

- Expertise: Applied linguists were tasked with the creation, implementation and ongoing operational management of the program. Senior disciplinary representatives cooperated in its set-up.

- Consultation: Stakeholders across the spectra of academics, school and committee leaders, administrators, pathway providers, financiers and marketers were included and/or informed during planning and development, either through membership of the ELWP or by consultation with it.

- Time: The ELWP spent one year undertaking the complex developmental work to set up the program. Teaching buy-out was arranged for curriculum developers.

- Unity: Disparate stakeholders displayed goodwill and/or were persuaded of the need for the program. Strong leadership from the DVC (Academic) was key in achieving this.

- Resourcing: The University allocated strategic funds in the program's first five years. Three full-time lecturers were appointed in LAL, the ELI appointed two academic managers and engaged over 25 sessional tutors, and an administrative officer was hired. Resourcing was also directed to research and evaluation.

- Educational integrity: The ELWP considered recommendations of best practice in the literature and received advice from the University's applied linguists on key theories. A research component was built into the model going forward to entrench the culture of educational integrity.

- Sustainability: All undergraduate university degree programs were restructured to accommodate the ELECs. Thus, it was not an 'add-on', a pilot, or a temporary project, but a fully functioning cog in the institutional machine.

Five years have passed since commencement. As mentioned in The Australian's feature article, the ELEC experiment is being observed by other universities with a view to possible implementation. The following section is, therefore, the heart of the matter. We report on the key issues that have emerged since inception and, where these issues have proved problematic, offer strategies and solutions based on experience.

\section{Part 4: Issues emerging from practice}

\section{Stakeholder perceptions}

An unintended consequence of a university-wide ELEC model is that it can foster and perpetuate the so-called 'silver bullet' fallacy: the mistaken view that students' academic language and literacy 'problems' can be 'solved' by application of a single mechanism 
(Barrett-Lennard, Dunworth, and Harris 2011). The purpose of an ELEC is to enhance academic language and learning, not to 'fix' students' English in a thirteen-week semester. Unrealistic expectations may be fed by the English language teaching industry standard which uses the guideline of ten weeks of intensive English language study (200-250 hours) for a typical gain of 0.5 of an IELTS bandscore. Such an outcome is not comparable with a one-semester undergraduate course of only 52 hours of in-class study (Humphreys, Haugh, Fenton-Smith, Lobo, Michael and Walkinshaw 2012; Storch 2009).

An important preventative measure is to engage with stakeholders from the outset to ensure they have a realistic, research-based understanding of what can be achieved. Research has shown that language acquisition is a slow process; writing, for example, does not develop substantially over one (or even three) years in an undergraduate degree program (Craven 2012; Humphreys et al. 2012; Knoch, Rouhshad and Storch 2014; Storch 2009). Sophisticated communication with staff at all levels (academic, managerial and administrative) is necessary to prevent inaccurate assumptions disseminating through faculties, programs and eventually to students themselves. As part of the course orientation, students should be informed of the expected linguistic outcomes, so that they are disabused of the quick-fix myth and, instead, formulate long-term learning objectives.

A second challenge is that, paradoxically, the increased institutional attention to language enhancement can lead to the disengagement of some academics from the EAP issues pertinent to their teaching practices. The stand-alone nature of the ELEC strategy may play to the perception by some academics that academic literacy is someone else's business. This perception is well documented in the literature, with several explanations proposed. Firstly, few academics have expertise in language learning/teaching and may struggle to comprehend and respond to students' language needs (Arkoudis and Starfield 2007). Secondly, many academics and administrators assume that a generalised approach to academic writing and reading can be taught which will apply to all contexts and across all disciplines, taking the view that "the acquisition of academic literacy involves a few hours of fixing up grammar in the language centre” (Hyland and Hamp-Lyons 2002, 6). Thirdly, some academics are simply unenthused, viewing academic language and learning as "mechanical and uninteresting” (Chanock 2007, 273). For all these reasons, some discipline lecturers may welcome a self-contained EAP strategy but view it as a license for disengagement. Thus, the ELEC model ought not be sold as a solution, but as one part of a wider blueprint that requires the participation of all concerned parties, as suggested by Arkoudis and Doughney (2014) in their distributed responsibilities model.

Finally, the legitimacy of an ELEC program is enhanced when it is not only researchbased but also research-generating, and thereby viewed as more than a learning and teaching initiative. Our experience has been that the involvement of facultied applied linguists is crucial in promoting the program's credibility in the eyes of the wider staff community, particularly through the visibility of program-focused research outputs.

\section{Student reception}

Student attitudes and expectations are key affective variables for second language learning. While fulfilled expectations foster a productive learning environment, unfulfilled expectations contribute to de-motivation, disengagement and even attrition (Bordia, Wales, Gallois, and Pittam 2011). Experience shows that the ELEC model has implications for student retention and attrition. 
Compulsory credit-bearing EAP courses may meet resistance from students who feel that they have already passed all necessary language hurdles prior to commencing their degree. Some may resent being obliged to complete a course that others (e.g. domestic English speakers) do not have to take, and therefore view it as remedial. Some may not see the relevance of language study to content study. A further concern for university administrators operating in the competitive international education market is that negative student perceptions may result in lower international enrolments (Lobo and Gurney 2013). Conversely, it might be argued that such a program demonstrates the institution's commitment to assisting EAL learners.

In our experience, certain strategies can effectively mitigate against negative student sentiment. Firstly, the credit-bearing nature of the course is a positive, since it does not extend the length of a degree. Secondly, students are presented in class with research findings explicating connections between improved language skills and graduate employability (e.g. Australian Education International 2010; Blackmore et al. 2014). Finally, discipline-specific content tends to defuse initial resistance as students see that the course is oriented to their chosen fields and is not a generic language program. Lobo and Gurney's (2013) survey of the University's ELEC students found that over two thirds would have taken it as an elective even if it was not compulsory.

\section{Materials development}

The first challenge for materials development relates to the specificity of content within a context of disciplinary diversity. For fiscal reasons alone, ELECs are more likely to be pitched at the level of academic field (e.g. business) than discipline (e.g. accounting). However, it is challenging to make course content equally relevant to all students' disciplines. For example, persuasive writing may be of interest to a journalism major but less so to a digital design major - yet both students would take the Arts and Social Sciences ELEC in which persuasive writing is taught. One solution is to build curricular units around concepts that resonate across related disciplines. In the Health ELEC, for example, students complete readings and related tasks under the umbrella theme of 'self-efficacy', a concept that is equally applicable in nursing, psychology, social work and medicine (see FentonSmith 2012). Another solution is to build a materials bank large enough to facilitate individualised learning in multi-disciplinary cohorts. In the Sciences ELEC, students select from a bank of discipline-specific reports (architecture, aviation, IT etc.) and apply generic tools of text deconstruction to the report from their area of study.

This leads to a second issue: who develops the materials? Barnard and Zemach (2003, 307) note that "the more focused the course, the greater the knowledge of the specialism required by the course designer". ELECs with multi-disciplinary foci therefore require multiple designers - which is costly - unless one person with an exceptionally broad range of specialised knowledge can be found. Moreover, discipline academics may be neither prompt nor enthusiastic in providing access to their authentic materials, making the designer's job yet more onerous.

A further question is what type of materials to use. Flowerdew and Peacock (2001) state that the first decisions for materials designers in academic language courses are whether to use published or in-house materials and, if the latter, whether authentic or non-authentic. To make the University's ELECs as relevant as possible to students' other studies, a decision was taken to create tailor-made materials. A large proportion of these were authentic, either professionally produced (e.g. a content textbook extract or journal article from the discipline), 
student-generated (e.g. a video of students authentic oral presentations) or content instructorgenerated (e.g. a discipline lecturer's assessment task). Original materials were then created that guide students through task-based analyses of these three types of authentic content (for an example see Fenton-Smith, 2013). Also, pedagogical guides were created for instructors that shadow all syllabus units. These guides not only assist teachers in delivering the material, but ensure uniformity of instruction across a large program involving many staff teaching in multiple locations, and which is under scrutiny from a variety of stakeholders.

\section{Program management}

Organisation and governance are major issues for a university-wide strategy. This involves at least three parties: administrators (responsible for financial management, enrolment, timetabling and grading processes), language specialists (curriculum development, teaching, research and evaluation), and academic schools (to cater for an ELEC in their degree programs). Reaching consensus on any aspect of program design, policy or implementation is inevitably time-consuming, so it is important that operational matters are anticipated and addressed prior to implementation rather than ad hoc after the program's launch. Our experience led to the creation of detailed policies for deciding which students do and do not have to take the course (see link at Footnote 2), and a procedure for screening and informing them.

A related issue is ongoing communication between stakeholders. The large-scale, multi-strand nature of the program can stifle the flow of information between the various entities. Ad hoc policy changes made without the knowledge of all stakeholders are a risk. To counteract these possibilities, centralised leadership is important to ensure stable governance, and a forum and medium for communication needs to be established prior to implementation. This may take the form, as in our case, of an English language working party comprising representatives from the various stakeholder bodies.

\section{Assessment}

The ELEC model raises several questions about assessment practices. These issues arise from three characteristics which make the course unlike most standard courses: subject matter (academic language and culture), language background (all students are EAL), and class size (large cohorts drawn from across the university).

Regarding the subject matter, we must consider what is being assessed in this course: achievement (typical of university course outcomes) or proficiency. In the fields of applied linguistics and language testing these two concepts are generally contrasted, with proficiency defined as "the degree of skill with which a person can use a language, such as how well a person can read, write, speak or understand language” (Richards, Platt and Platt 1992, 204). Achievement, on the other hand, is described as "language ability as a result of learning" (Richards et al. 1992, 204). In reality, these two concepts are not entirely dichotomous but it is vital to give explicit consideration to this matter to ensure validity of assessment. In the University's implementation of the ELECs, a combined approach was adopted - what has been referred to as prochievement (Pino 1989; Stansfield 1990) - because we were interested in both 'ability as a result of learning' (achievement) as well as 'the degree of skill' (proficiency). To achieve this, items are assessed using analytical criteria referenced against both achievement and proficiency. Some aspects of the assessment criteria are based on the objectives of the course (Hughes 2003; Smith and Lovat 2003) such as key genres, academic referencing and the apposite use of discipline-specific vocabulary. Proficiency, on the other 
hand, is considered by reference to the minimum standard required to commence undergraduate studies at the university. That is, a Pass on any assessment item is considered equal to the demonstration of proficiency at the minimum entry level to the University, while a Distinction could only be gained by those evidencing language at the level where students are exempt from the course, i.e. IELTS 7 or above.

The second factor, language background, has a bearing on perceptions of grade integrity. There has been recent controversy within Australian higher education about the effect on grades of large numbers of EAL (particularly international) students within courses. Research by Foster $(2012,596)$ concluded that "the presence of more NESB [non-English speaking background] students in a course buoys up the marks of all students in that course" and that this may reflect "downward adjustments to the difficulty of material or grading standards applied when large concentrations of such students are present in a course”. This leads to consideration of whether ELEC grades are commensurate with those obtained in other credit-bearing courses. One argument is that fewer high grades should be expected because the cohort's English language ability is lower. However, although a student with high-level academic English would likely obtain a high grade in an ELEC, such students are barred from enrolling by a policy which restricts access from students with English as a first language whose aim is to inflate their GPA. For those legitimately enrolled, the course is not an easy option because it is pitched at their expected levels of achievement and proficiency, as outlined above. To ensure this, we explored correlations between IELTS Academic test scores and the GPAs of participants in the same semester, both including and excluding ELECs from the cumulative GPA (Humphreys et al. 2012). The results were almost identical, evidencing that ELEC grades do not artificially inflate GPAs.

The third characteristic, the large cohort size drawn from across the University (and therefore the large number of assessors required), makes the reliability of grading crucial yet challenging to address. Standardised marking procedures are necessary to ensure that students are graded consistently and fairly. This includes the use of criterion-referenced marking, analytic (as opposed to global) scoring, and staged assessment using the teaching-learning cycle to scaffold support through both formative and summative tasks (Hughes 2003; Hyland 2013; Cross and O'Loughlin 2013). Reliable grading is also enhanced through face-to-face tutor moderation sessions for major written assignments and an equivalent process for oral presentations via a self-access moderation kit. These practices are further supported by a tutor induction day run prior to every semester and by the production of a Tutor Handbook for ongoing reference.

\section{Measuring outcomes}

A final vexing question for the ELEC model is how to demonstrate that it works. Due to its university-wide public face, the pressure to validate its implementation is high. Administrators expect results to justify the magnitude and expense of the operation. Faculties expect results to justify making room in their degree programs. Students need reassurance that they are not wasting time and money by undertaking more language study. Governmental accreditation and quality assurance agencies may also expect universities to demonstrate effectiveness in the development of students' English language competency. We outline three approaches to measuring outcomes that we have used. However, we caution that institutional stakeholders need to be made aware of the complex and protracted nature of language learning and the confounding variables, many of them external to formal instruction, which complicate attempts to quantify linguistic development. 
One method of evaluating a program is student evaluations, such as centrally administered post-semester questionnaires. In our case, quantitative and qualitative student response data was closely scrutinised by the ELWP and used to make curriculum adjustments. While we welcomed the positive results and consistent improvement over five years, this was tempered by our knowledge that such surveys can be "predominantly measures of student satisfaction, as opposed to measures reflecting aspects relevant to student learning” (Bedggood and Donovan 2012, 826). Confounding variables abound, whether they be student-related (e.g. expectations, grades), teacher-related (e.g. grading leniency, likeability), or course-related (e.g. class size, content difficulty) (Denson, Loveday and Dalton 2010). Additional sources of evaluation were therefore required to mitigate these concerns.

A second approach is to map the program against national benchmarks or standards such as the DEEWR Good Practice Principles (DEEWR 2009). We utilised the latest national language planning and policy guidelines in preparation for internal and external audits, ELWP meetings, funding reviews, national award applications, stakeholder information sessions and public presentations as a way of illustrating how the ELEC program meets externally prescribed standards of 'best practice'.

A third approach is to examine objective measures such as students' GPAs or language test score changes in relation to their ELEC performance. Baik and Grieg (2009) and Storch and Hill (2008) linked participation in EAP courses to significant GPA gains. We similarly evaluated ELEC, finding that GPAs correlated strongly with end-of-semester IELTS scores for reading and listening, though not with writing and speaking (Humphreys et al. 2012). Our study also found that low initial scorers on IELTS improved the most by the end of semester, suggesting that ELEC was supporting those most in need. Other findings demonstrated a significant difference in GPA $(t(2134)=7.27, p<=.01, r=.32)$ for international students who had completed an ELEC $(M=4.57)$ compared to those who had not $(M=4.36)$. The small to moderate effect size provides some evidence of positive learning outcomes across the degree lifecycle. A caveat is that language proficiency tests such as IELTS or TOEFL may lack the sensitivity to isolate shifts resulting from a single 52-hour course. Even where student language development over this time could be demonstrated, it would be difficult to attribute changes to ELEC due to the myriad of other variables which affect language learning. Measuring outcomes using test scores is therefore useful but unlikely to evidence large increases. We argue, therefore, that this method should be used in conjunction with richer, more qualitative data for a fuller understanding of the impact.

\section{Conclusion}

This paper has reflected on issues emerging from the implementation of a university-wide approach to English language enhancement. It contributes to an ongoing discussion in English-medium higher education regarding ways to support the English language development of EAL students and to increase their chances of success in culturally and linguistically diverse academic environments. It should be noted that the ELECs only constitute one part of the broader English Language Enhancement Strategy in the University, albeit the widest-reaching, and therefore the one most likely to prompt fundamental structural shift within the institution. This model is not presented as a universal cure-all for inadequate academic English; arguably, the remarkable achievement of this strategy is that an entire institution - including all its elements and the senior executive - was prepared to collaborate and sacrifice so that a radical restructuring could occur, as a result of which students now focus squarely on the nature of academic language in their degree programs from day one. 
Our hope is that this paper has cogently shared the large number of practical, pedagogical and philosophical challenges inherent in the model and suggested effective strategies for resolving them.

\section{References}

Academic Quality Agency (AQA) for New Zealand Universities. 2013. Cycle 5 Academic Audit Framework. http://www.aqa.ac.nz/cycle5framework

Arkoudis, S., C. Baik, and S. Richardson. 2012. English Language in Higher Education: From Entry to Exit. Camberwell: ACER.

Arkoudis, S., and L. Doughney. 2014. Good Practice Report - English Language Proficiency. Sydney: Office for Learning and Teaching. http://www.cshe.unimelb.edu.au/research/teaching/docs/GPR_English_language_2014. pdf

Arkoudis, S., and S. Starfield. 2007. “In-course Language Development and Support.” Paper presented at the National Symposium: English Language Competence of International Students, Sydney, Australia, August 14.

Australian Education International. 2010. International Graduate Outcomes and Employer Perceptions. Australian Education International, Canberra. https://aei.gov.au/research/Publications/Documents/2010_International_Graduate_Outc omes.pdf

Bachman, L., and A. Palmer. 2010. Language Assessment in Practice. Oxford: Oxford University Press.

Baik, C., and J. Greig. 2009. “Improving the Academic Outcomes of Undergraduate ESL Students: The Impact of a Discipline-Specific Intervention Program for First-Year Architecture Students." Higher Education Research and Development Journal 28 (4): 401-416.

Barnard, R., and D. Zemach. 2003. “Materials for Specific Purposes.” In Developing Materials for Language Teaching, edited by B. Tomlinson, 306-323. London: Continuum.

Barrett-Lennard, S., K. Dunworth, and A. Harris. 2011. “The Good Practice Principles: Silver Bullet or Starter Gun?” Journal of Academic Language and Learning 5 (2): 99-106.

Bedggood, R., and J. Donovan. 2012. "University Performance Evaluations: What are We Really Measuring?” Studies in Higher Education 37 (7): 825-842.

Benesch, S. 2001. Critical English for Academic Purposes: Theory, Politics, and Practice. New York and London: Routledge.

Birrell, B., L. Hawthorne, and S. Richardson. 2006. Evaluation of the General Skilled Migration Categories. Department of Immigration and Multicultural Affairs: Canberra, Australia. http://www.immi.gov.au/media/publications/research/gsm-report/index.htm

Blackmore, J., C. Gribble, L. Farrell, M. Rahimi, R. Arber, and M. Devlin. 2014. Australian International Graduates and the Transition to Employment. Australian Research Council Linkage Project LP0990815 and IDP Education Pty Ltd. Australian Research 
Council. http://www.deakin.edu.au/research/src/crefi/documents/internationalgraduates-employment.pdf

Bordia, S., L. Wales, C. Gallois, and J. Pittam. 2011. "Antecedents and Consequences of TESOL Student Expectations.” Australian Review of Applied Linguistics 31 (2): 15.115.18.

Canale, M. 1984. “On Some Theoretical Frameworks for Language Proficiency.” In Language Proficiency and Academic Achievement, edited by C. Rivera, 28-40. Avon: Multilingual matters Ltd.

Canale, M., and M. Swain. 1980. "Theoretical Bases of Communicative Approaches to Second Language Teaching and Testing.” Applied Linguistics 1 (1): 1-47.

Chanock, K. 2007. "What Academic Language and Learning Advisors Bring to the Scholarship of Teaching and Learning: Problems and Possibilities for Dialogue with the Disciplines.” Higher Education Research and Development 26 (3): 269-280.

Cho, J., and H. Yu. 2015. "Roles of University Support for International Students in the United States: Analysis of a Systematic Model of University Identification, University Support, and Psychological Well-Being”. Journal of Studies in International Education 19 (1): $11-27$.

Craven, E. 2012. “The quest for IELTS 7.0: Investigating English Language Proficiency of International Students in Australian Universities.” IELTS Research Reports 13: 1-61. Canberra: IELTS Australia.

Cross, R., and K. O’Loughlin. 2013. “Continuous Assessment Frameworks within University English Pathway Programs: Realizing Formative Assessment within High-Stakes Contexts.” Studies in Higher Education 38 (4): 584-594.

Denson, N., T. Loveday, and H. Dalton. 2010. "Student Evaluation of Courses: What Predicts Satisfaction?” Higher Education Research and Development 29 (4): 339-356.

Department of Education, Employment and Workplace Relations (DEEWR). 2009. Good Practice Principles for English Language Proficiency for International Students in Australian Universities. Canberra: DEEWR. http://www.aall.org.au/sites/default/files/Final_ReportGood_Practice_Principles2009.pdf

Duff, P. 2010. “Language Socialization into Academic Discourse Communities.” Annual Review of Applied Linguistics 30: 169-192.

Dunworth, K., H. Drury, C. Kralik, and T. Moore. 2014. "Rhetoric and Realities: On the Development of University-Wide Strategies to Promote Student English Language Growth.” Journal of Higher Education Policy and Management 36 (5): 520-532.

Fenton-Smith, B. 2012. "Facilitating Self-Directed Learning amongst International Students of Health Sciences: The Dual Discourse of Self-Efficacy.” Journal of Academic Language and Learning 6 (1): 64-76.

Fenton-Smith, B. 2013. “The Application of Discourse Analysis to Materials Design for Language Teaching.” In Applied Linguistics Applied: Applications of Theories of 
Applied Linguistics to Materials Development for Language Learning, edited by B. Tomlinson, 127-141. London: Continuum.

Fenton-Smith, B., and Michael, R. 2013. "Mandatory Trialling of Support Services by International Students: What They Choose and How They Reflect.” Teaching in Higher Education 18 (8): 933-949.

Flowerdew, J., and M. Peacock. 2001. “The EAP Curriculum: Issues, Methods, and Challenges.” In Research Perspectives on English for Academic Purposes, edited by. J. Flowerdew and M. Peacock, 177-194. Cambridge: Cambridge University Press.

Forest, J., and P. G. Altbach, eds. 2006. International Handbook of Higher Education Vol. 1. Dordrecht: Springer.

Foster, G. 2012. “The Impact of International Students on Measured Learning and Standards in Australian Higher Education.” Economics of Education Review 31: 587-600.

Habel, C. 2009. “Academic Self-Efficacy in ALL: Capacity-Building for Self-Belief.” Journal of Academic Language and Learning 3 (2): 94-104.

Hall, J. 2009. "WAC/WID in the Next America: Redefining Professional Identity in the Age of the Multilingual Majority.” The WAC Journal 20: 33-49.

Hughes, A. 2003. Testing for Language Teachers. Cambridge: Cambridge University Press.

Humphreys, P., M. Haugh, B. Fenton-Smith, A. Lobo, R. Michael, and I. Walkinshaw. 2012. "Tracking International Student English Proficiency over the First Semester of Undergraduate Study.” IELTS Research Reports Online Series 1: 1-41. Canberra: IELTS Australia.

Hyland, K. 2002. "Authority and Invisibility: Authorial Identity in Academic Writing." Journal of Pragmatics 34 (8): 1091-1112.

Hyland, K. 2006. English for Academic Purposes: An Advanced Resource Book. London and New York: Routledge.

Hyland, K. 2013. "Writing in the University: Education, Knowledge and Reputation." Language Teaching 46 (1): 53-70.

Hyland, K., and L. Hamp-Lyons. 2002. “EAP: Issues and Directions.” Journal of English for Academic Purposes 1: 1-12.

Kennelly, R., A. Maldoni, and D. Davies. 2010. “A Case Study: Do Discipline-Based Programmes Improve Student Learning Outcomes?” International Journal for Educational Integrity 6 (1): 61-73.

Knoch, U., A. Rouhshad, and N. Storch. 2014. "Does the Writing of Undergraduate ESL Students Develop after One Year of Study in an English-Medium University?” Assessing Writing 21: 1-17.

Kramsch, C. 1986. “From Language Proficiency to Interactional Competence.” The Modern Language Journal 70 (4): 366-372. 
Kramsch, C. 2006. “From Communicative Competence to Symbolic Competence.” The Modern Language Journal 90 (2): 249-252.

Lea, M., and B. Street. 1998. "Student Writing in Higher Education: An Academic Literacies Approach.” Studies in Higher Education 23 (2): 157-172.

Lea, M., and B. Street. 2006. “The ‘Academic Literacies’ Model: Theory and Applications.” Theory into Practice 45 (4): 368-377.

Lobo, A., and L. Gurney. 2013. "What Did They Expect? Exploring a Link Between Students' Expectations, Attendance and Attrition in the English Language Enhancement Courses.” Journal of Further and Higher Education 38 (5): 730-754.

Mahboob, A., S. Dreyfus, S. Humphrey, and J. Martin. 2010. “Appliable Linguistics and English Language Teaching: The Scaffolding Literacy in Adult and Tertiary Environments (SLATE) Project.” In Appliable Linguistics, edited by A. Mahboob and N. Knight, 25-43. London: Continuum.

Marginson, S., C. Nyland, E. Sawir, and H. Forbes-Mewett. 2010. International Student Security. Cambridge: Cambridge University Press.

Murray, N. and S. Nallaya. 2014. "Embedding Academic Literacies in University Programme Curricula: A Case Study.” Studies in Higher Education ahead-of-print: 1-17.

Nunan, D. 1997. “Designing and Adapting Materials to Encourage Learner Autonomy.” In Autonomy and Independence in Language Learning, edited by P. Benson and P. Voller, 192-203. London: Longman.

OECD. 2013. Education at a Glance 2013: OECD Indicators. Paris: OECD Publishing. http://www.oecd.org/edu/eag2013\%20(eng)--FINAL\%2020\%20June\%202013.pdf

OECD. 2014. Education at a Glance 2014: OECD Indicators. Paris: OECD Publishing. http://www.oecd.org/edu/Education-at-a-Glance-2014.pdf

O’Loughlin, K., and S. Arkoudis. 2009. “Investigating IELTS Exit Score Gains in Higher Education.” IELTS Research Reports 10, 1-90. Canberra: IELTS Australia.

Pennycook, A. 1997. “Vulgar Pragmatism, Critical Pragmatism, and EAP.” English for Specific Purposes 16 (4): 253-269.

Pino, B. 1989. "Prochievement Testing of Speaking.” Foreign Language Annals 22 (5): 487496.

Quality Assurance Agency (QAA). 2009. Thematic Enquiries into Concerns about Academic Quality and Standards in Higher Education in England Final Report - April 2009. http://www.qaa.ac.uk/Publications/InformationAndGuidance/Documents/FinalReportA pril09.pdf

Richards, J., J. Platt, and H. Platt. 1992. Dictionary of Language Teaching and Applied Linguistics. Essex, UK: Longman.

Rochecouste, J., R. Oliver, D. Mulligan, and M. Davies. 2011. “The English Language Growth Project.” Australian Universities Review 53 (1): 102-104. 
Sheridan, V. 2011. “A Holistic Approach to International Students, Institutional Habitus and Academic Literacies in an Irish Third Level Institution.” Higher Education 62 (2): 129_ 140.

Smith, D. and T. Lovat. 2003. Curriculum: Action on Research. 4th ed. Victoria: Cengage.

Stansfield, C. 1990. "Some Foreign Language Test Development Priorities for the Last Decade of the Twentieth Century.” Foreign Language Annals 23 (5): 395-401.

Storch, N. 2009. "The Impact of Studying in a Second Language (L2) Medium University on the Development of L2 Writing.” Journal of Second Language Writing 18: 103-118.

Storch, N., and K. Hill. 2008. "What Happens to International Students' English after One Semester at University?” Australian Review of Applied Linguistics 31 (1): 3.1-3.17.

Swales, J. 1990. Genre Analysis: English in Academic and Research Settings. Cambridge: Cambridge University Press.

Swales, J. 2011. “Coda: Reflections on the Future of Genre and L2 Writing.” Journal of Second Language Writing 20 (1): 83-85.

Thaiss, C., and T. Porter. 2010. "The State of WAC/WID in 2010: Methods and Results of the US Survey of the International WAC/WID Mapping Project." College Composition and Communication 6 (3): 534-570.

Trounson, A. 2010. “[The University] Makes English Refresher Mandatory.” The Australian, February 17. http://www.theaustralian.com.au/higher-education/griffith-makes-englishrefresher-mandatory/story-e6frgcjx-

1225831097095?nk=60fec054607b30f982f7ddded12c0086

Wilkinson, R. 2013. "English-Medium Instruction at a Dutch University: Challenges and Pitfalls”. In English-Medium Instruction at Universities: Global Challenges edited by A. Doiz, D. Lasagabaster and J-M. Sierra, 3-24. Bristol: Multilingual Matters.

Wingate, U. 2006. “Doing Away with 'Study Skills'.” Teaching in Higher Education 11 (4): 457-469.

Wingate, U., N. Andon, and A. Cogo. 2011. "Embedding Academic Writing Instruction into Subject Teaching: A Case Study.” Active Learning in Higher Education 12 (1): 69-81.

Wingate, U., and C. Tribble. 2012. "The Best of Both Worlds? Towards an English for Academic Purposes/Academic Literacies Writing Pedagogy.” Studies in Higher Education 37 (4): 481-495.

Zepke, N., and L. Leach. 2010. "Improving Student Engagement in Post-Compulsory Education: A Synthesis of Research Literature." A report prepared for Teaching and Learning Research Initiative, Wellington, New Zealand.

Zhengdong, G. "IELTS Preparation Course and Student IELTS Performance: A Case Study in Hong Kong." RELC Journal 40 (1): 23-41. 